Military Technical College Kobry El-Kobbah, Cairo, Egypt

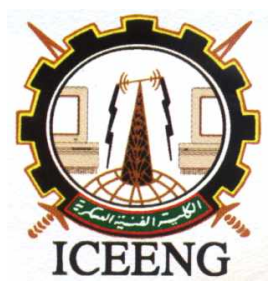

\author{
$6^{\text {th }}$ International Conference \\ on Electrical Engineering \\ ICEENG 2008
}

\title{
New approach regarding the cinematic characteristics analysis of circuit breakers
}

By
M. Adam*
S. Pispiris **
A. Baraboi*
C. Pancu*

\section{Abstract:}

The paper presents the required parameters in the evaluation of the technical state for the High Voltage (HV) circuit breakers. It details some aspects regarding the influence of the cinematic characteristics to the circuit breakers performances. Also, it presents a possibility to use the artificial neural network (ANN) in the analysis of the circuit breakers cinematic characteristics, in order to diagnostic their technical state.

\section{Keywords:}

circuit breaker, cinematic characteristics, artificial neural network

* "Gh. Asachi” Technical University, Iasi, Romania

** Transelectrica Company, Bucharest, Romania 


\section{Introduction:}

The maintenance policy of the circuit breakers is oriented to corrective maintenance (realized after the failure) and on the scheduled preventive maintenance, that is realized after pre-established criteria (for example time periods, number of short circuit disconnections).

Today, it follows to changing the scheduled preventive maintenance with that predictive maintenance, which is realized in accordance with the technical state of equipment. In order to establish and prediction the technical state of the electrical equipment the monitoring and diagnostic activities are required.

The HV circuit breakers monitoring and diagnostic are orientated to their functions and constructive sub-ensemble (e.g. insulation, the switching function, the operating mechanism etc.).

In Table 1, the used parameters in diagnostic and monitoring of the circuit breakers $\left(\mathrm{SF}_{6}\right.$, oil) are presented, with the specification of the importance of each parameter in these activities, [1], [4], [5]. 
Table (1): Parameters for the circuit breaker monitoring and diagnostic

\begin{tabular}{|c|c|c|c|}
\hline $\begin{array}{c}\text { Function } \\
\text { / sub-ensemble }\end{array}$ & Parameter / characteristic & Monitoring & Diagnostic \\
\hline \multirow[t]{8}{*}{ Switching } & Contact resistance & - & $\mathrm{M}$ \\
\hline & Contact temperature & $\mathrm{L}$ & - \\
\hline & Current load & $\mathrm{M}$ & - \\
\hline & Main contacts position & $\mathrm{H}$ & - \\
\hline & $\begin{array}{l}\text { Cinematic characteristics (motion, speed, } \\
\text { acceleration) }\end{array}$ & $\mathrm{M}$ & $\mathrm{M}$ \\
\hline & Acting time, non-simultaneity & $\mathrm{M}$ & $\mathrm{M}$ \\
\hline & Arcing time & $M$ & - \\
\hline & Electroerosion & $\mathrm{M}$ & - \\
\hline \multirow[t]{8}{*}{ Insulation } & $\mathrm{SF}_{6}$ density & $\mathrm{H}$ & - \\
\hline & Partial discharges & - & $\mathrm{L}$ \\
\hline & Oil level & $\mathrm{L}$ & $\mathrm{H}$ \\
\hline & Oil quality & $\mathrm{M}$ & $\mathrm{H}$ \\
\hline & Moisture in $\mathrm{SF}_{6}$ & - & $\mathrm{M}$ \\
\hline & $\mathrm{SF}_{6}$ purity & - & $\mathrm{L}$ \\
\hline & Main contacts position & $\mathrm{H}$ & $\mathrm{M}$ \\
\hline & Gas temperature & $\mathrm{H}$ & - \\
\hline \multirow{6}{*}{$\begin{array}{l}\text { Operating } \\
\text { mechanism }\end{array}$} & Operating number & $\mathrm{M}$ & $\mathrm{M}$ \\
\hline & Operating time & $\mathrm{M}$ & $\mathrm{M}$ \\
\hline & Stored energy & $\mathrm{H}$ & - \\
\hline & Cinematic characteristics & $\mathrm{M}$ & $\mathrm{M}$ \\
\hline & Motor state & $\mathrm{M}$ & $\mathrm{M}$ \\
\hline & Vibration signatures & $M$ & $\mathrm{M}$ \\
\hline \multirow{4}{*}{$\begin{array}{c}\text { The control and } \\
\text { auxiliary } \\
\text { circuits }\end{array}$} & Supply voltage & $\mathrm{H}$ & $\mathrm{H}$ \\
\hline & Current in coils & $\mathrm{M}$ & $\mathrm{H}$ \\
\hline & Continuity of the circuits & $\mathrm{M}$ & $\mathrm{H}$ \\
\hline & Auxiliary switches state & $\mathrm{M}$ & $\mathrm{H}$ \\
\hline
\end{tabular}

Note: The importance of the parameters: H-high; M-medium; L-low.

\section{Cinematic characteristics:}

Between the parameters with a special importance in the knowledge of the HV circuit breakers technical state, and cinematic parameters are included (the total motion, the motion in contact, the opening/closing speed, opening/closing time, non-simultaneity time between poles, respective between the chambers of the same pole), they influencing directly their performances, [1], [2], [3]. 
Thus, the cinematic parameters strongly influence the contacts electroerosion, puffer nozzle wearing (for the $\mathrm{SF}_{6}$ circuit breakers), arc extinction chamber wearing and quality decreasing of insulation and ignition environment of electric arc.

In order to obtain the cinematic characteristics of the HV circuit breakers, in generally it uses the motion recording method (linear or angular) from an accessible point of the cinematic chain of the mobile contacts. Exist many possibilities for motion recording: with drummer, numerical, with oscilloscope with memory etc, [1], [5].

Comparing the motion of mobile contact vs. time, obtained at the circuit breaker operation, with a motion, normal considered, for that circuit breaker it can determinate a series of abnormal situation which can appears in its operation. For example, in Figure 1 are shown the comparing between the normal opening motion (1) and the motions (2) obtained in different abnormal situations: a) delays in the operation of opening electrical valve, caused by the existence of a high friction; b) low speed at opening because of the energy decreasing charged in the operating mechanism; c) inadequate absorption given by the wearing of opening damper; d) too small distance between contacts, because of incorrect assembling, [1].

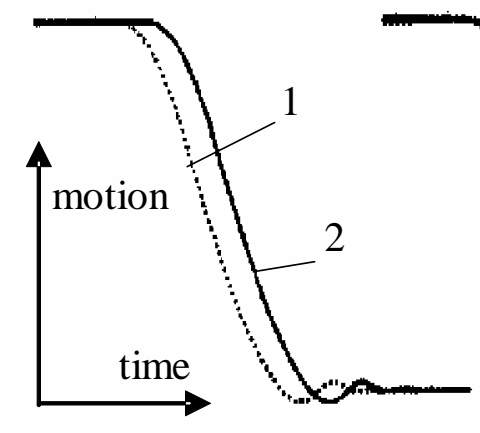

a)

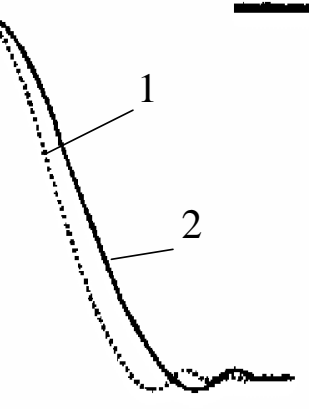

b)

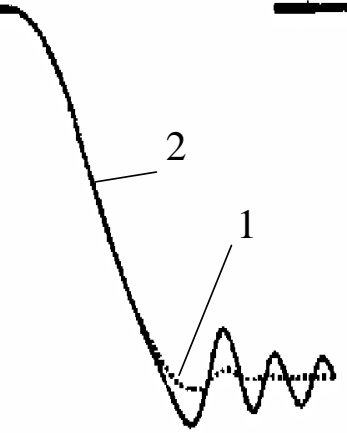

c)

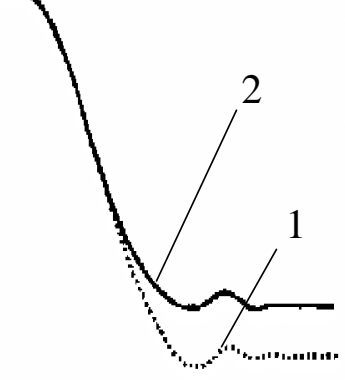

d)

Figure (1): The motion of mobile contact at disconnection in normal situation (1), abnormal respectively (2)

Generally, the determination methods of the cinematic characteristics are methods used during the circuit breakers maintenance and these follows the validation of these activities (for example, the replacement of a high pressure pipes, can leads to the introduction of a supplementary hydraulic resistance and in this way, to the modifying of the cinematic parameters). They are not methods used in the cinematic characteristics monitoring of the circuit breaker when this is under voltage.

It presents a possibility for monitoring and diagnostic of cinematic characteristics of the electrical equipment using the artificial neural networks. The required database which to include all possible situations in the operation of equipment has determined the modelling of the mechanical system of motion drive, using the systems of electrical nature, with RLC elements, [1]. 


\section{Modelling of mechanical system}

It considers an linear mechanical system with a single degree of freedom made from the mass $\mathrm{m}$, at which acts the excitation force $\mathrm{F}(\mathrm{t})$, the elastic force given by the spring characterised by the de elasticity constant $\mathrm{K}$ and the viscous absorption force proportional with the speed given by a damper, that has the absorption coefficient $r$, Figure 2a.

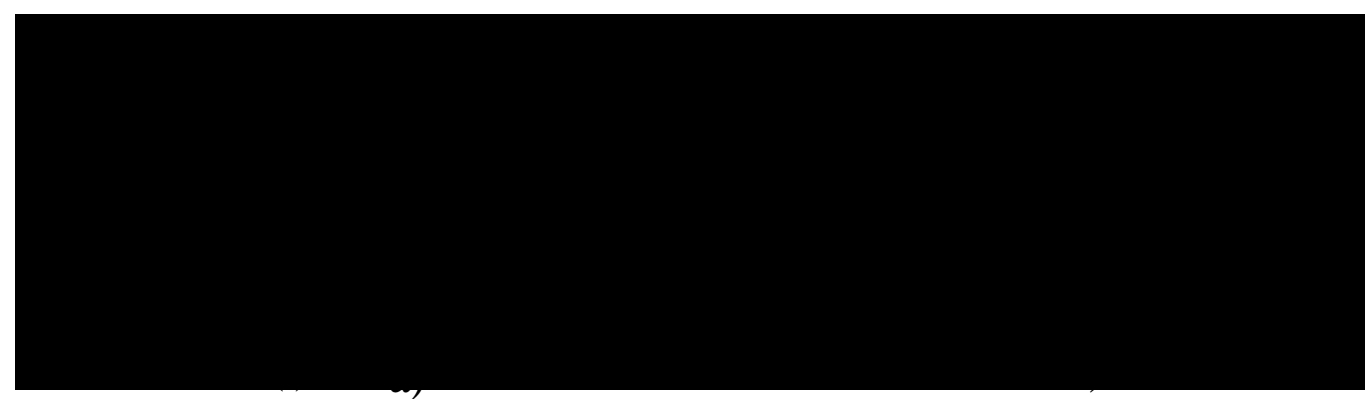

Figure (2): a) Mechanical system with a single degree of freedom; b) RLC series circuit

Applying the dynamic equilibrium low it obtains the following equation which describe the response time of the mechanical system:

$m \frac{d^{2} x}{d t^{2}}+r \frac{d x}{d t}+K \cdot x=F(t)$

For the series electrical circuit form Figure $2 b$, the differential equation which describes its response is:

$\mathrm{L} \frac{\mathrm{d}^{2} \mathrm{q}}{\mathrm{dt}^{2}}+R \frac{\mathrm{dq}}{\mathrm{dt}}+\frac{1}{\mathrm{C}} \cdot \mathrm{q}=\mathrm{u}(\mathrm{t})$

It can consist that the both systems are described by the differential equations of the same shape. If it put in correspondence the measurements:

$\mathrm{u}(\mathrm{t})$, supply voltage $\Leftrightarrow \mathrm{F}(\mathrm{t})$, excitation force of the mechanical system; $\mathrm{q}(\mathrm{t})$, electric charge $\Leftrightarrow \mathrm{x}(\mathrm{t})$, mechanical moving (motion);

$\mathrm{R}$, electrical resistance $\Leftrightarrow \mathrm{r}$, absorption coefficient;

$\mathrm{L}$, electrical inductance $\Leftrightarrow \mathrm{m}$, mass;

$1 / C$, inverse of capacity $\Leftrightarrow K$, elasticity constant;

then, the behaviour of the mechanical system from Figure $2 \mathrm{a}$ can be studied using the electrical circuit form Figure $2 b$, based on the above correspondences. 
Because of the fact that the mechanical system for motion drive of the circuit breakers suppose the existence of much more moving mechanical elements, it is necessary a dynamic replacement of the entire system with a single element, called reference element. Thus, if it has a motion of translation then it will has assigned a reduce mass and a reduce force of the entire system. In the case of a motion of rotation of the reference element, similarly it talks about the reduce moment of inertia and reduce moment of force, also.

For the circuit breakers mechanical system, choosing a reference (point) element (usually it chooses the operating place of the main active force or on the mobile contact) and calculating the reduce mass (reduce moment of inertia) and reduce force (reduce moment of force), respectively, it could describe the motion of the mechanical system using the equation (1), where $\mathrm{m}$ will be reduce mass, while $\mathrm{F}(\mathrm{t})$ reduce force.

The concept of reduce mass (reduce moment of inertia) is introduced on the base of equilibrium between the kinetic energy of the reduce mass (reduce moment of inertia) and the kinetic energy of all elements from the system.

The concept of reduce force (reduce moment of force) results from the equality's principle between the elementary mechanical work realised by the reduce force applied into a determined mode on the reference element, and the sum of the elementary mechanical work realised by the forces that operate to the all system elements.

The mechanical system can be modelled, having in view the relations between the mechanical and electrical parameters, using some series circuits which includes resistances, inductances and capacitors.

Using the electrical circuits which represent the model of mechanical system of motion drive, it can study the transient processes of the system and determinate the cinematic parameters of the circuit breakers, for the closing and opening operation, in different situations.

\section{The analysis of the cinematic characteristics:}

In the analysis of the cinematic characteristics of the circuit breaker an ANN has been used with the architecture including three layers complete connected. The input layer receives the mobile contact curve, $\mathrm{X}(\mathrm{t})$, numerical determined using RLC model, but discretised in 30 points, while from the output layer it obtains the equipment's status (normal - abnormal). For the abnormal state the causes which have conducted to an incorrect operation are presented. 


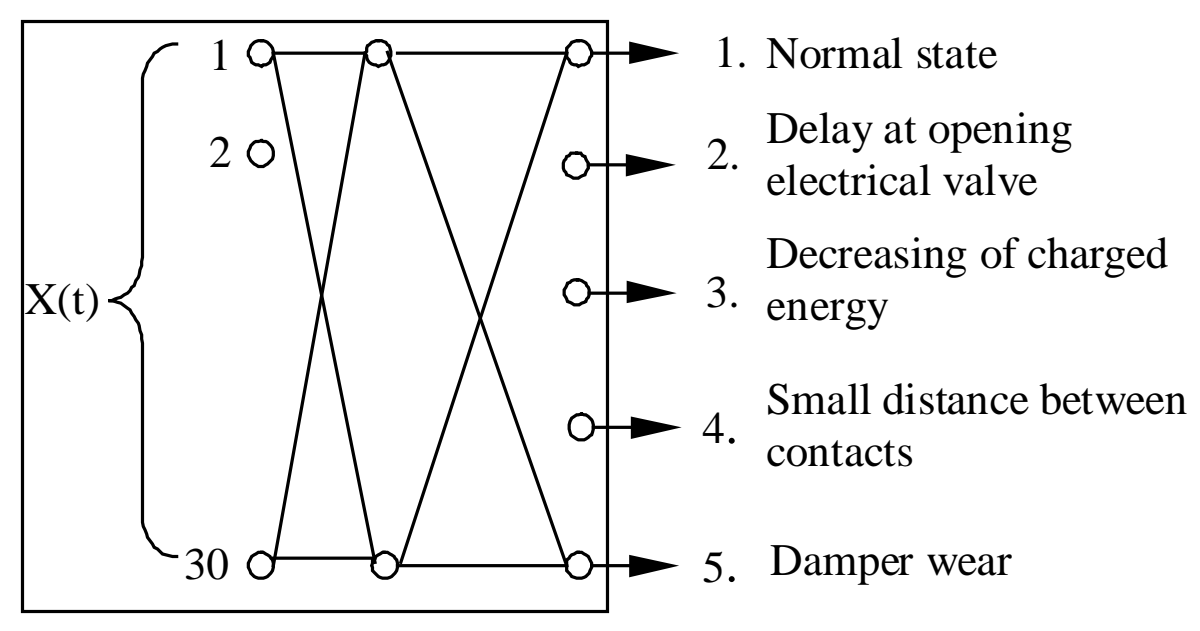

Figure (3): ANN architecture for the monitoring of cinematic characteristics

The used ANN, in this application, has the architecture described in Figure 3, [1], [4]. The optimal topology of the ANN contains the input layer with 30 neurons, 50 on the hidden layer and, 5 on the output layer, respectively.

The technical state of the circuit breaker, looking from the point of view of cinematic characteristics, will be indicated at the ANN output through the neuron's activation in accordance with the respective state, by switching from 0 state in 1 .

The learning data set has been generated using the electrical model of the mechanical system of motion drive from circuit breaker, after the reducing of the mass and of the forces, this being simulated with the help of a RLC circuit, corresponding to the opening and closing operations.

Through the repeated calculus and excluding the situations for which the technical restrictions are exceeded, it has obtained a learning data base which contains 350 inputoutput models. The ANN is trained using the training data obtained choosing different percents from the total of learning database.

After how it can see in Figure. 4, 10 hours has been necessary for training of an ANN using $90 \%$ from the learning database. It consists that the training time necessary is linear according with the number of data used. Then, the ANN has been tested using the characteristics that haven't been used in the learning process. 


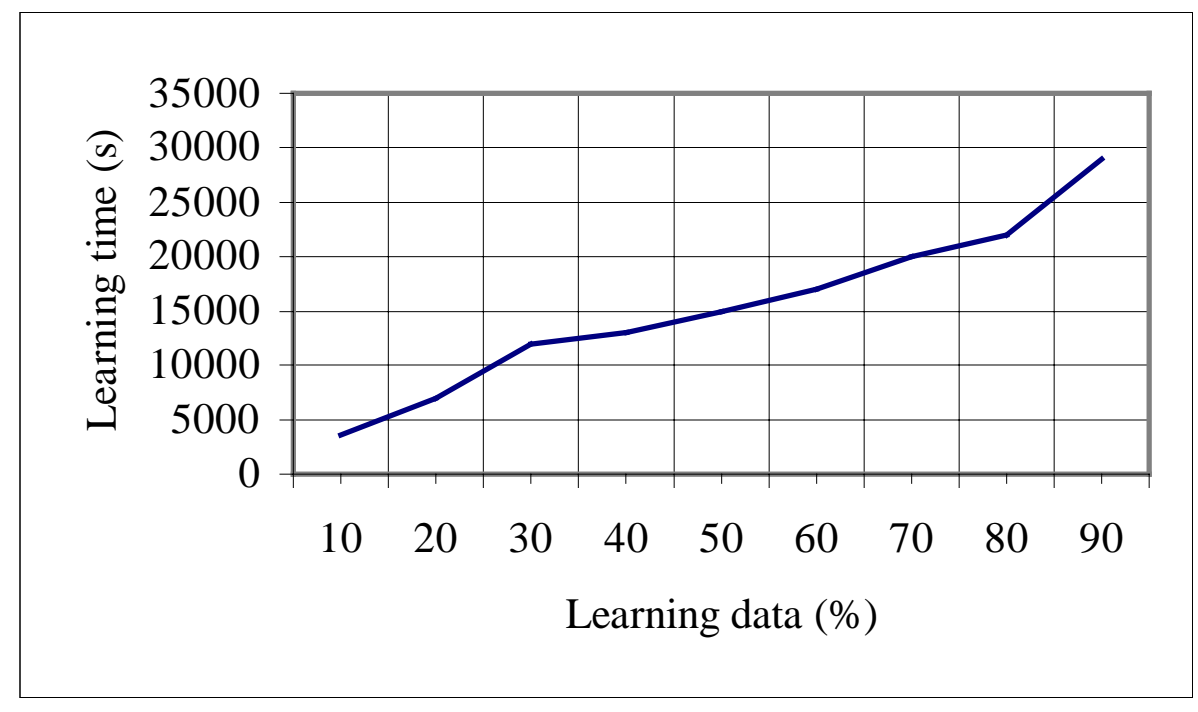

Figure (4): Learning time vs. used learning data

For example, applying a cinematic characteristic at the ANN input having the shape similar with that from Figure 1a, the ANN has activated the output 2, Figure 3, which corresponds with a delay of the opening electrical valve, given by the existence of some high frictions, those outputs remaining inactive.

It can appreciate that the ANN can be successfully used in the technical state diagnostic of the circuit breaker knowing the cinematic characteristics. Thus, through the analysis of the mobile contact curve it can determinates various abnormal situations appeared in the cinematic system of circuit breaker.

\section{Conclusions:}

The HV circuit breakers monitoring and diagnostic are orientated to their functions and constructive sub-ensemble (e.g. insulation, the switching function, the operating mechanism etc.), existing a big number of parameters that are used in these activities.

In the estimation of the circuit breakers technical state a great importance have their cinematic parameters. Thus, these strongly influence the contact electroerosions, puffer nozzle wearing (for the $\mathrm{SF}_{6}$ circuit breakers), arc extinction chamber wearing and quality decreasing of insulation and ignition environment of electric arc, etc.

In the field of electrical equipment, in the world, a great attention is focused on the use of artificial intelligence in their monitoring, diagnostic and control.

The ANN can be successfully used for diagnostic of circuit breakers technical state based on their cinematic characteristics. Thus, through the curve analysis of the mobile contact it can determinates various failures appeared at the cinematic system of the circuit breaker like as: delays in the operation of electrical valves, too small distance between contacts, damper wearing, decreasing of charged energy, etc. 


\section{References:}

[1] M. Adam, C. Pancu and A. Baraboi, Structuri hardware-software în construcția echipamentelor electrice inteligente, Editura VENUS, Iaşi, 2006, ISBN 973-756031-0.

[2] M. Adam, A. Baraboi and C. Pancu, About the monitoring and diagnostic of the circuit breakers, The XIII ${ }^{\text {th }}$ International Symposium on High Voltage Engineering, Delft, Holland, p. 4, 2003, ISBN 90-77017-79-8-CD-ROM.

[3] A. L. J. Janssen, W. Degen, C. R. Heising, H. Bruvik, E. Colombo, A summary of the final results and conclusions of the second international enquiry on the reliability of high voltage circuit breakers". Proceedings CIGRE'94, Paris, paper 13.202, 1994.

[4] C. Pancu, A. Baraboi and M. Adam, Study on cinematic characteristics of switchgears using artificial intelligence, The $\mathrm{V}^{\text {th }}$ International World Energy System Conference, Oradea, Romania, pp. 342-345, 2004.

[5] * * *, User Guide for the Application of Monitoring and Diagnostic Techniques for Switching Equipment for Rated Voltages of $72,5 \mathrm{kV}$ and Above, CIGRE WG 13-09, 2000. 